\title{
POR UMA EDUCAÇÃO DO CAMPO QUE CONTEMPLE AS PARCERIAS NOS PROCESSOS FORMATIVOS E AS FORMAS IDENTITÁRIAS DOS POVOS DO CAMPO
}

\author{
TOWARDS A RURAL EDUCATION AND PARTNERSHIPS \\ IN TEACHER TRAINING AND RURAL IDENTITIES
}

Priscila Andrade Magalhães Rodrigues*

\begin{abstract}
Resumo: Este ensaio acadêmico constitui um esforço analítico quanto às questões que emergem sobre a produção em educação do e no campo, de modo a pensar uma proposta que contemple a construção de parcerias entre os envolvidos no movimento "por uma educação do campo" e que considere as formas identitárias dos povos do campo. Buscou-se, primeiramente, a partir da literatura dedicada ao tema, levantar as principais questões ligadas à educação do campo, em momento de grande efervescência de estudos e produção acadêmica sobre o assunto. Em um segundo momento, buscou-se reconhecer o lugar da escola do campo na formação de docentes e ,especialmente, o estabelecimento de parcerias entre universidade, movimentos sociais, ONGs e demais parceiros e as escolas do campo, na tentativa de fomentar processos formativos que articulem teoria e prática, e que atentem para as questões identitárias dos povos do campo e sua luta por reconhecimento social. Por fim, buscou-se olhar especialmente para a legislação e compreender como a questão da identidade dos povos do campo é tratada nos textos legislativos, e trazendo as contribuições analíticas para a construção da identidade dos povos do campo, na perspectiva de que toda análise cultural precisa considerar a complexidade da relação social entre os sujeitos.
\end{abstract}

Palavras-chave: Educação do campo. Escola do campo. Parcerias. Formação de professores. Formas identitárias.

\begin{abstract}
This article is an attempt to analyze the questions that come from the academic production on rural education in order to develop a proposal "towards a rural education" that takes into consideration the partnerships between those involved in the movement considering the rural identities. Firstly, based on what had already been written about the theme, the study tried to raise questions related to rural education, especially at a moment when a large number of studies and production about the subject is emerging. Furthermore, the role of rural schools in teacher training has been taken into consideration, especially the partnerships between universities, social movements, NGOs, other partnerships and the rural schools, in an attempt to foster teacher training processes that deal with theory and practice, and that considers questions regarding rural identities and their struggle for social recognition. Finally, legislation related to the theme has been analyzed in order to understand how rural identities are dealt with in legal texts, and to come up with analytical contributions to the building of rural identities, from the perspective that every cultural analysis needs to consider the complexity of social relations between the subjects.
\end{abstract}

Keywords: Rural education. Rural school. Partnerships. Teachers training. Identities.

\footnotetext{
${ }^{*}$ Doutoranda e mestre em educação pela Pontifícia Universidade Católica do Rio de Janeiro (PUC-Rio). Professora do Colégio Brigadeiro Newton Braga (CBNB). E-mail: <priscilaapri@gmail.com>
} 


\section{Introdução}

Este ensaio constitui um esforço analítico sobre as questões que emergem sobre a produção em educação do e no campo, de modo a pensar uma proposta que contemple a construção de parcerias entre os envolvidos no movimento "por uma educação do campo" e as formas identitárias dos povos do campo. Buscou-se primeiramente, a partir da literatura dedicada ao tema, levantar as principais questões ligadas à educação do campo, em momento de grande efervescência de estudos e produção acadêmica sobre o assunto.

Em um segundo momento, buscou-se reconhecer o lugar da escola do campo na formação de docentes, e especialmente o estabelecimento de parcerias entre universidade, movimentos sociais, ONGs e demais parceiros e as escolas do campo, na tentativa de fomentar processos formativos que articulem teoria e prática, e que atentem para as questões identitárias dos povos do campo e sua luta por reconhecimento social.

Por fim, buscou-se olhar especialmente para a legislação e compreender como a questão da identidade dos povos do campo é tratada nos textos legislativos, e trazer contribuições analíticas para a construção da identidade dos povos do campo, na perspectiva de que toda análise cultural precisa considerar a complexidade da relação social entre seus sujeitos.

Nosso objetivo é trazer outros olhares para se pensar a educação do campo com foco no sujeito do campo, de modo que a proposição de estudos e políticas tenha claros o sujeito e sua complexa relação com outros e com o seu meio. Trata-se de um ensaio acadêmico que visa a acrescentar às discussões atuais sobre a educação do campo a atenção para os sujeitos do campo e suas relações, propondo a consolidação de parcerias no processo de construção de uma educação do e no campo.

\section{Breve contexto}

É recente o lugar da educação no campo nas políticas públicas, nas instâncias municipais, estaduais e federais. Neste último âmbito, até a Constituição de 1988, a educação rural, nomenclatura utilizada até 1998, ocupou lugar completamente marginal com relação à responsabilidade do estado em mantê-la, o que é explicado pela própria proposta da educação básica no Brasil, cuja abertura para "todos" só ocorreu nesse momento. A necessidade de uma educação rural já aparecia nas Constituições de 1934 e 1937, no entanto, nunca houve uma discussão sobre qual educação e como seria o tipo de oferta a ela. Os textos das Constituições de 1946, 1967 e 1969 seguiram responsabilizando ou excluindo a responsabilidade das empresas agrícolas pela oferta de educação a seus trabalhadores, bem como para os filhos destes, tendo surgido nessas discussões a proposta de oferta do salário educação para suprir essa demanda. Somente com a Constituição de 1988, quando a educação é afirmada como dever do Estado e direito público de todo sujeito, independentemente de os cidadãos residirem nas áreas urbanas ou rurais, ela começa a ganhar espaço para a discussão sobre estratégias e metodologias de trabalho, de modo a atender a esse público.

Fundamentais para o processo de trazer o debate sobre educação rural para dentro da agenda política são os movimentos sociais, que ocupam lugar central, especialmente o Movimento dos Sem Terra. Como ressalta Vendramini (2007), a educação do campo surge a partir da luta social, da mobilização de trabalhadores diante das 
precárias condições de trabalho e sobrevivência. Assim, a educação do campo foi sendo "incorporada" na agenda de lutas de variados movimentos sociais e sindicais do campo, contando com o envolvimento, inclusive, de órgãos públicos.

Em 1996, a Lei de Diretrizes e Bases da Educação (LDB) esclarece, em seu artigo 23, que a organização da educação básica pode se dar através de

séries anuais, períodos semestrais, ciclos, alternância regular de estudos, grupos não-seriados, com base na idade, na competência e em outros critérios, ou por forma diversa de organização, sempre que o interesse do processo de aprendizagem assim o recomendar.

Além disso, a LDB traz a importância de organizar o currículo seguindo uma base nacional comum e outra de diversidade, para que cada sistema de ensino considere as peculiaridades locais na composição desse currículo. O artigo 28, voltado para a oferta de educação básica para a população rural, enfatiza que os sistemas de ensino serão os responsáveis por promover "as adaptações necessárias à sua adequação às peculiaridades da vida rural e de cada região” no que diz respeito aos conteúdos curriculares, metodologias de ensino voltadas para as necessidades e interesses dos alunos; organização escolar própria, bem como o calendário escolar adequado ao trabalho do campo; e por fim, adequação ao tipo de trabalho na zona rural.

Fruto da mobilização dos movimentos sociais, em 1998 foi organizada pelo MST, CNBB, UNICEF e UNESCO a Conferência “Por uma educação básica no campo”. Essa conferência, de âmbito nacional, é considerada como marco da ruptura entre pensar em uma educação rural (o modelo existente) e uma educação do e no campo que tem como protagonistas os sujeitos coletivos, ou seja, todos aqueles que se unem à causa do campo, à luta pela educação de qualidade para todos. O principal compromisso da educação do campo é com a construção da vida de forma sustentável, seja ela no campo ou na cidade.

A mudança de nomenclatura educação do campo e não mais educação rural, mesmo que esta última esteja presente na legislação, se dá, portanto, como uma ruptura com a oferta de educação pensada para meios urbanos, sem a preocupação com a luta camponesa como sujeitos de direitos.

Vários seminários e eventos aconteceram com o objetivo de se pensar na proposta de uma educação do campo. Como conquista dessa luta, em 2004 foram aprovadas as "Diretrizes Operacionais para a Educação Básica nas Escolas do Campo", cujo objetivo foi o de adequar a educação do campo às demais diretrizes nacionais que regem toda a educação básica, orientando a organização escolar, currículo e financiamento da educação. A partir daí surgem diferentes demandas para a educação do campo, tendo como carro-chefe as propostas de formação de professores.

Depois de 12 anos de luta dos movimentos sociais por uma educação do campo, foi aprovado o Decreto $n^{\circ}$. 7.352, de 4 de novembro de 2010, que "dispõe sobre a política de educação do campo e o Programa Nacional de Educação na Reforma Agrária - PRONERA" (BRASIL, 2010). Esse documento afirma que o objetivo da política de educação do campo é “ampliação e qualificação da oferta de educação básica e superior às populações do campo” (Ibidem). A responsabilidade da educação do campo fica a cargo da União em colaboração com os Estados, o Distrito Federal e os Municípios, considerando as diretrizes e metas estabelecidas no Plano Nacional de Educação. 
É interessante ressaltar que a população do campo é definida no documento a partir de uma base produtiva, não apenas com relação ao espaço ou ao ambiente rural ocupado. Ela é formada por

agricultores familiares, os extrativistas, os pescadores artesanais, os ribeirinhos, os assentados e acampados da reforma agrária, os trabalhadores assalariados rurais, os quilombolas, os caiçaras, os povos da floresta, os caboclos e outros que produzam suas condições materiais de existência a partir do trabalho no meio rural. (BRASIL, 2010, grifo meu).

Esse olhar para o sujeito do campo como aquele cuja existência está estritamente ligada à produção do meio rural vai ao encontro de estudos da sociologia rural, que tem questionado os limites entre rural e urbano e interferido na construção identitária desses sujeitos, como veremos mais adiante.

Com relação às demais características do documento, há ênfase de que cada escola do campo, ou seja, cada escola situada em área rural ou urbana, desde que atenda à população do campo, elabore seu projeto político-pedagógico (P.P.P.) específico, articule processos de investigação, desenvolvimento social e sustentável com o mundo do trabalho. A ênfase para a efetivação da escola do campo é proposta no documento por meio da formação inicial e continuada de professores, garantia de infraestrutura e transporte, materiais e livros didáticos específicos, biblioteca, área de esporte, laboratórios, sempre buscando atender ao P.P.P. da escola e à diversidade local.

O documento ainda ressalta a necessidade de se pensar em várias questões: flexibilidade do calendário; pedagogia da alternância (especialmente para o Ensino Médio e Superior); classes multisseriadas, especialmente nos anos iniciais; alimentação escolar de acordo com as especificidades e características da região do campo; inclusão digital para essa população; e elaboração de material didático.

A repercussão do documento na comunidade do campo parece ser positiva, porém é mais uma conquista que precisa ser efetivada através de ações reais, de políticas efetivas. Esta é, sem dúvida, uma boa notícia para a educação do campo, entretanto origina aquilo que Nóvoa (2007, p. 23) considera como uma má notícia para a educação, já que "o excesso dos discursos esconde uma grande pobreza das práticas”.

\section{Políticas de formação docente}

Praticamente toda literatura que emerge sobre a construção de uma educação do campo tem buscado refletir sobre as questões presentes no Decreto $n^{0} 7.352$, especialmente sobre o lugar que a formação docente ocupa nesse processo. Arroyo (2007) aponta para importantes considerações que também indicam essa centralidade. Para ele, a "história nos mostra que não temos uma tradição nem na formação de políticas públicas, nem no pensamento e na prática de formação de profissionais da educação que focalize a educação do campo e a formação de educadores do campo como preocupação legítima” (ARROYO, 2007, p. 158). Essa afirmativa do autor, que poderia ser expandida para toda falta de investimento em políticas públicas de educação voltadas para a população dos meios rurais, pode ser entendida, segundo ele, a partir de duas hipóteses.

A primeira hipótese refere-se à lógica do sistema educacional brasileiro, que é urbana; logo, toda a agenda política está ancorada no paradigma urbano. Nesse aspecto, o campo é percebido como “o outro lugar” 
que precisa ser desenvolvido dentro dos padrões urbanos. Nessa perspectiva, a escola, seu currículo, alunos e professores precisam adaptar-se às condições do campo, mas em uma lógica de educação escolar urbana. Ivanilde Apoluceno, em encontro na PUC-Rio, em junho de 2010, chamou esse processo de "urbanocentrismo", termo que se apresenta como bastante adequado ao processo tal como ele ocorre. Ainda segundo esta lógica, muitas vezes há deslocamento do aluno do campo para a escola urbana, ou professores que compartilham da lógica urbana e que lecionam em escolas rurais.

Outros problemas levantados por Arroyo (2007) são as propostas de nucleação de escolas. A educação rural com suas especificidades, especialmente com relação ao número de crianças de cada região, pauta-se no trabalho através das classes multisseriadas, ou seja, normalmente as escolas, unidocentes, funcionam sem a lógica da seriação escolar. Várias crianças de faixa etária e desenvolvimento pedagógico diferentes estudam juntas, já que nem sempre as regiões rurais dispõem de estrutura e recursos humanos suficientes para formar várias turmas. Assim, o professor - que também é faxineiro, diretor, líder da comunidade - assume todas as funções administrativas da escola, além de sua função como docente. O Plano Nacional da Educação (2001) tem por objetivo ofertar o ensino fundamental em todos os recantos do país, de modo que haja "ampliação da oferta das quatro séries (agora cinco anos) regulares em substituição às classes isoladas unidocentes", sem deixar de considerar as "peculiaridades regionais e a sazonalidade". Esse objetivo culminou no processo de nucleação de escolas, descrito por Arroyo (2007) e Hage (2010): crianças de determinada região do campo viajam para cidades urbanas para estudar em escolas maiores, saindo de suas realidades.
A segunda hipótese apontada por Arroyo para a não existência de políticas voltadas para o campo/educadores do campo é representada pelo caráter generalista das políticas públicas; logo, pela falta de políticas públicas e ações afirmativas para coletivos específicos, como populações do campo. Para Arroyo, a ênfase na afirmação da educação de qualidade para todos foi um avanço, mas não pode fechar-se em si mesma, pois a proclamação de políticas generalistas não dá conta de garantir os direitos de tantos outros "em gênero, classe, raça, etnia e território" (ARROYO, 2007, p.161). Por tal razão, os movimentos sociais afirmam que esses "outros" são sujeitos de direitos. Portanto, terra, território, cultura e educação são constituintes da identidade dos povos do campo. A escola precisa, pois, ser do e no campo, bem como seus professores, já que normalmente o professor urbano não conhece as tensões, conflitos e problemas vivenciados pela população do campo. Por isso, a compreensão do vínculo entre terra, território e escola deve nortear a formação de educadores do campo.

Até o momento, a ausência de políticas e de instituições voltadas para as especificidades da formação de educadores faz com que os movimentos sociais busquem estratégias para suprir essa ausência. Várias são as experiências isoladas de formação de professores, especialmente para atuarem nos primeiros anos do ensino fundamental.

Vendramini (2007) destaca o grau de inovação presente nas diferentes ações socioeducativas, formais e não formais, que se desenvolvem no interior dos movimentos sociais e em outros espaços como sindicatos e cooperativas, com o objetivo de preparar seus educadores. Para a autora, esses processos articulam uma grande capacidade de mudanças dos sujeitos, dentro de sua realidade. Há, portanto, um repensar sobre o lugar da escola para além dela, em uma perspectiva 
de formação política. Observa-se, por exemplo, que

os movimentos sociais do campo, entre eles o MST, têm pressionado não só pela Reforma Agrária e por uma política agrícola que viabilize a pequena produção no campo, mas também por uma educação e escolarização para uma população historicamente alijada das políticas públicas. Ainda que o Movimento esteja envolvido diretamente nas lutas por uma educação do campo, seu projeto de formação vai mais além, ao desenvolver ações políticas que em si são educativas e ao direcionar a formação não só para o aspecto técnico e escolar, mas essencialmente político. (VENDRAMINI, 2007, p. 133).

Por outro lado, as primeiras experiências de licenciatura em educação do campo foram encabeçadas por quatro universidades do país: UFMG, em 2004; UnB, em 2007; UFS e UFBa, em 2008, a partir de incentivo. Sempre em parceria com movimentos sociais, desde o projeto de organização dos cursos, estes têm por princípio preparar profissionais do campo para atuarem como docentes e gestores dos processos educativos escolares e comunitários. Tais cursos possuem como proposta a formação por áreas de conhecimento, de modo a preparar os profissionais para atuarem em toda a educação básica e não apenas nos anos iniciais. Assim, o profissional preparado nessa perspectiva pode organizar a educação escolar dos estudantes camponeses até o ensino médio. As propostas enfatizam a formação por alternância, ou seja, a alternância entre comunidade e universidade. Dentro dessa lógica, há tentativa de diálogo entre o tempo que os estudantes passam em suas casas e o tempo que eles passam na universidade. Na prática, há muitos desafios para que esse diálogo efetivamente ocorra, já que estudos (ROCHA; MARTINS, 2010) demonstram o isolamento dos estudantes durante o tempo comunidade, e mesmo a pouca leitura realizada por esses estudantes quando estão em suas comunidades.

Todavia, não se pode pensar que as propostas de formação em colaboração entre universidade ou espaços de formação e comunidade se apresentem como um caminho sem dificuldades. Porém, esse é um caminho necessário e indispensável na preparação de docentes e líderes para atuarem na educação do campo.

\section{Práticas escolares no campo}

As propostas de educação formal buscam pautar-se basicamente no princípio de que os sujeitos do campo são sujeitos participantes; logo, o diálogo é fundamental para o processo de aprendizagem. Um trabalho nessa direção é partir da busca constante de informações dos locais de origem dos estudantes, de modo que estes se reconheçam como sujeitos ativos na sociedade. Souza (2008) ressalta a importância da prática da sala de aula a partir da construção, com a participação de toda a comunidade, de projetos escolares cujos temas, oriundos de dentro da comunidade, organizariam os conteúdos a serem estudados. Desse modo, os temas geradores propostos por Paulo Freire encontram lugar na prática pedagógica, sendo seus norteadores. Um trabalho pautado em tais princípios permitiria uma melhor articulação entre os conteúdos e valorização da experiência extra-escolar dos estudantes, trazendo-a para dentro da escola.

As propostas que normalmente buscam organizar a lógica escolar com a lógica do campo baseiam-se na proposta pedagógica que articula o chamado tempo comunidade-tempo escola ou pedagogia da 
alternância. A alternância é entendida como possibilidade de abertura do mundo escolar à realidade dos alunos, garantindo a flexibilização da organização do calendário escolar, adequando-o à vida do campo, e também visando à aplicação dos conhecimentos escolares à realidade dos estudantes.

Segundo Silva (2010), a formação por alternância no Brasil, criada na década de 60 pelas Escolas de Família Agrícola (EFA) no Espírito Santo, e também utilizada posteriormente pelas Casas Familiares Rurais (CFR) em Alagoas, na década de 80, recentemente foram aglutinadas em uma rede nacional denominada Centros Familiares de Formação por Alternância (CEFFAS), que conta com mais de 270 experiências de formação. Há atualmente diferentes experiências que se utilizam da alternância pedagógica como eixo de seu processo educativo. Podemos citar ainda os Programas Saberes da Terra, Residência Agrária e Empreendedorismo do Jovem Rural, e outras propostas realizadas nas mais diferentes instâncias e modalidades, as quais se apresentam como importante caminho ao processo de formação, mas também apresentam dificuldades. Silva (2010), que reconhece o lugar da alternância nos processos de formação escolar do campo, ressalta que na prática a alternância tem sido normalmente uma justaposição de atividades. Ou seja, a prática de alternância não tem dado conta de articular os saberes da vida aos saberes escolares, não tem associado as atividades propostas de vivência no meio familiar com as atividades dos programas de formação.

Tomando como exemplo o estudo de Souza (2008) em escolas localizadas em assentamentos da reforma agrária no estado do Paraná, estudo esse que buscou caracterizar a prática pedagógica de 60 professores, podemos perceber alguns aspectos a serem pensados na educação do campo, com en- foque sobre o planejamento pedagógico, a proposta curricular, os conteúdos e projetos escolares, e a metodologia de ensino. A autora entende ser pertinente trazer os resultados desse estudo como exemplo das questões que envolvem a prática pedagógica do campo, em proposta que desponta como atenta em pensar uma educação que atenda adequadamente e especificamente diferentes grupos sociais, como camponeses e quilombolas. Segundo Souza, vários municípios no estado do Paraná têm criado coordenadorias de educação no campo, as quais, além de discutirem os projetos de ensino nas escolas do campo, propiciam espaços de formação continuada docente.

Com relação ao planejamento pedagógico, normalmente a cargo das coordenadorias acima mencionadas, foi identificada pela pesquisadora uma ressalva com relação à produção reflexiva e pedagógica do MST e outros movimentos sociais, não chegando à realidade escolar. Ao se tratar da proposta curricular de educação do campo, não há clareza entre os professores entrevistados sobre sua configuração. Há apenas a sugestão de que as propostas de Paulo Freire representam um caminho para se pensar na educação do campo. Quanto aos conteúdos escolares, estes devem sempre partir da realidade dos alunos, segundo os professores. Há, no entanto, um conflito entre organizar o conteúdo seguindo as orientações oficiais, ou organizá-lo a partir daquilo que o professor julgue importante, fazendo as possíveis relações entre o oficial e a realidade do aluno. A metodologia de ensino, bastante variada, enfoca leitura, aulas expositivas, rodas de conversa, trabalhos em grupo, desenhos e outras atividades, sendo fortemente marcada pelo incentivo à comunicação. Por fim, os projetos escolares, a partir dos temas de interesse dos alunos, são considerados como o melhor caminho para aproximar o universo escolar 
do universo de vida do estudante do campo. Pois, através da metodologia de projetos é possível envolver toda a comunidade escolar em um projeto comum e também dialogar com outros espaços (outros assentamentos, por exemplo).

As constatações de Silva (2008) permitem ver que há um longo processo a percorrer na consolidação de uma educação do campo. A autora também afirma que a formação docente, como na escola urbana, é primordial para a garantia de uma educação de qualidade.

\section{A escola como espaço real de forma- ção profissional}

A preocupação dos estudiosos e demais envolvidos na educação do campo quanto à formação de professores é bastante legítima. Formar para o reconhecimento das subjetividades e das lutas dos povos do campo, como veremos, exige uma formação consistente, que articule os conteúdos teóricos às características dos sujeitos do campo e suas lutas por reconhecimento. Este é, na verdade, o cerne dos problemas quanto à formação de docente no mundo, a dificuldade entre a articulação da teoria e da prática aos contextos educacionais. Como Canário (2000) ressaltou, a educação do campo surge como meio de levantar alternativas para a educação, considerando o sujeito do campo e as práticas educacionais que o contemplem, trazendo contribuições para repensar a escola, seus sujeitos e suas práticas.

Nas últimas décadas, o reconhecimento da escola como espaço de formação de professores tem estado presente nas discussões da comunidade educacional (TARDIF, 1991, 2008; PERRENOUD, 1999; NÓVOA, 2000, 2007; CANÁRIO, 2005; ROLDÃO, 2006, 2007). Os autores citados destacam que é preciso reconhecer a escola como lócus da formação inicial e continuada de professores, de modo que "trabalhar e formar não sejam atividades distintas” (NÓVOA, 2002, p. 29). O fato de a formação docente para o campo privilegiar os sujeitos do próprio campo já é um avanço, pois o docente/futuro docente já está inserido em seu contexto social, podendo realizar melhor as associações entre a teoria e sua prática. As propostas de alternância entre os espaços de formação (universidades, movimento social etc.) e de campo (espaço social da prática, da vivência, da comunidade) precisam considerar tais espaços como necessários e articulados, e não distintos. É necessário, no entanto, evitar a simples justaposição de atividades sobre esses dois espaços nos cursos de formação, como destacou Silva (2010).

Roldão (2007), ao falar sobre a formação para a excelência profissional docente, ressalta que a formação profissional deve acontecer em qualidade científica, de modo que o professor assegure uma especificidade no saber de sua área. A autora reforça que cabe à formação centrar-se na ação profissional, para organizar o curso "em torno da sua função e do saber necessário ao desempenho profissional” (ROLDÃO, 2007, p. 40). Assinala que os saberes pedagógicos e científicos não devem ser pensados em alternância, e sim na "sólida construção de um saber científico-profissional integrador de todos os saberes que se mobilizam para a prática da ação de ensinar enquanto fazer aprender alguma coisa a alguém” (Idem, p. 37). A formação do professor, portanto, não deve pender para o lado da universitarização, tampouco para o da escolarização. Antes, deve haver uma colaboração entre esses dois níveis de ensino (e também, acrescento, entre os movimentos sociais, ONGs e outras instâncias formativas que fazem parte da construção da educação do campo), de modo que no "vaivém” entre 
o espaço da universidade e o da escola, ou entre a formação e o trabalho, possa, efetivamente, haver a necessária articulação entre os saberes teóricos e os saberes da experiência (CANÁRIO, 2001).

\section{Parcerias entre universidade, escola básica do campo, movimentos socais e outros atores do campo}

O reconhecimento da escola como espaço real de formação docente suscitou discussão quanto à importância da construção de parcerias entre universidade e escolas de educação básica na formação de professores. Acredito que tal discussão traz grandes contribuições para a educação do campo, principalmente ao ressaltar a importância do estabelecimento de parcerias entre os envolvidos nesse processo educacional. Como destaca Rocha (2010, p. 366),

o termo Educação do Campo é uma produção de sujeitos coletivos - movimentos sociais, universidades, organizações não governamentais, instituições públicas e religiosas, dentre outras. Sua gestação se dá nas lutas concretas dos acampados e assentados por escola. Nestas lutas vai se desvelando que a rede educacional rural além de não atender ao direito de acesso à educação básica também não garantia a permanência, qualidade da oferta, formação de professores, organização dos tempos e espaços adequados ao modo de vida das famílias, dentre outros. As reflexões sobre a produção desta precariedade vincularam a escola a um modelo de desenvolvimento que não inclui os trabalhadores e trabalhadoras do campo como sujeitos de direitos. Com esta compreensão a Educação do Campo surge como ruptura com o modelo de Educação Rural.

Avalorizadaparceriaentrediferentessujeitoséum aspecto marcante para o movimento por uma educação do campo. No simpósio "Educação no campo: convergências e tensões no campo da formação e do trabalho docente”, ocorrido no XV Endipe/2010, esse aspecto foi bastante ressaltado por todos os palestrantes. Para se construir uma educação do campo, entende-se como fundamental que seja uma produção, como enfatiza Rocha, de vários sujeitos, dos movimentos sociais, da universidade, das instituições públicas, e outras.

As parcerias são consideradas pela comunidade educacional como importante meio para fazer com que a formação de professores se constitua em percurso contínuo e coerente de desenvolvimento profissional (PERRENOUD, 1999; FOERSTE, 2004; CANÁRIO, 2007; NÓVOA, 2007; TARDIF, 2008;). Considerar a escola, a escola do campo, como local privilegiado de formação de professores é pressuposto para o estabelecimento de parcerias entre universidade e escola, entre movimentos sociais e outros movimentos que, juntos, promovam melhorias para a formação inicial e continuada dos docentes do campo, contribuindo para uma proposta de educação que contemple os sujeitos do campo como sujeitos de direitos.

A pesquisa internacional sobre a formação para o ensino mostra claramente que todos os programas de qualidade têm como característica comum a existência de parcerias fortes com o meio escolar, parcerias que tomam frequentemente a forma de “estabelecimentos formadores" [...] e não têm apenas um efeito positivo sobre a qualidade da formação dos docentes, mas também sobre o aprendizado dos alunos (TARDIF, 2008, p. 24).

Para Tardif, é necessário desenvolver “fortes” parcerias entre todas as instituições envolvidas no processo educativo, onde haja "um conhecimento comum e convicções partilhadas a respeito do ensino e da 
aprendizagem” (TARDIF, 2008, p. 9). Dessa forma, todos os envolvidos no processo educativo exercem o papel de co-formadores. Snoek (2007), defendendo a parceria entre universidade e escola, também considera que elas devem trabalhar em conjunto, compartilhando deveres e responsabilidades, em prol de objetivos comuns bem definidos. Nesse sentido, todas as instituições são beneficiadas.

O estabelecimento de parcerias entre as instituições e sujeitos que promovem a educação do campo favorece, portanto, a construção de propostas de inovação curricular, de desenvolvimento profissional de seus docentes, bem como o conhecimento sobre o processo de ensino e aprendizagem, promovendo novas alternativas para o trabalho docente e para a promoção da aprendizagem dos alunos. De modo especial, o estabelecimento de parcerias pode contribuir para que a formação docente e a construção de uma proposta de educação do campo sejam voltadas para as formas identitárias e as lutas por reconhecimento dos povos do campo.

\section{Formas identitárias dos povos do campo}

A mudança de nomenclatura - de educação rural para educação do campo - representa para o movimento "por uma educação do campo" a marca de luta por educação no e do campo, na perspectiva de que "o povo tem direito a ser educado no lugar onde vive; e o povo tem direito a uma educação pensada desde o seu lugar e com a sua participação, vinculada à sua cultura e às suas necessidades humanas e sociais" (CALDART, 2002, p.11).

Os poucos textos legislativos que tratam sobre a temática apresentam apenas dados estatísticos frios, excluindo as relações sociais desse povo, desses grupos que possuem características e formas organizacionais próprias. Há pouca ou quase nenhuma preocupação em pensar o sujeito do campo e sua identidade. Tais documentos trazem uma concepção de povos do campo numa visão obsoleta, ignorando as novas relações entre os sujeitos do campo e as mudanças socioeconômicas. O que se encontra neles são expressões como "respeito à diferença e políticas de igualdade”, atenção para as “especificidades culturais da população escolar” e palavras como "adaptação”, “adequação”, presentes nas constituições estaduais e demais documentos legislativos analisados pelas Diretrizes Operacionais para a Educação Básica das Escolas do Campo (BRASIL, 2001), o que evidencia a pouca preocupação da lei com a diversidade.

Estudos sobre a sociologia do rural apontam que não é possível "confinar (analiticamente) uma população nos limites do que se entende, hegemonicamente, como rural” (CARNEIRO, 2005, p.10). Em apresentação do livro Identidades sociais: ruralidades no Brasil Contemporâneo, Maria José Carneiro faz questão de salientar que há uma recente revitalização de regiões rurais no Brasil, fomentada por razões variadas como atividades consideradas urbanas; um novo olhar do meio urbano para a natureza como uma contemplação; uma modificação nos hábitos e valores urbanos por jovens rurais, o que gera uma recusa destes em seguirem as atividades de seus pais agricultores; o consumo de produtos de natureza simbólica, tidos como "naturais", "rurais” ou "tradicionais”. Esses são alguns fatores que, segundo a autora, têm levado a um repensar das categorias de análise sobre o rural, buscando-se novas alternativas.

A visão dualista cidade/campo, urbano/rural tem sido questionada por estudiosos. 
Lima (2005), a partir das colocações de Nicole Methieu, aponta que, posteriormente à década de 1990, houve mudanças na concepção do rural. Ela sintetiza tais mudanças como "anos de tensões disruptivas (queda do socialismo, reforço de movimentos étnicos e liberalização agrícola crescentes, crise do desemprego/globalização e crise ambiental - aguizados nos 1990, mas originados em 1980 - ideologia do desenvolvimento local e políticas de descentralização)" (LIMA, 2005, p. 45). Todas essas tensões levaram a uma mudança de olhar para o rural, que, no discurso, como salienta a autora, passa a ser visto como "o campo", patrimônio, paisagem, natureza e memória, que precisam ser preservados. "Assim, o rural aparece como paisagem natural a ser preservada e o papel do agricultor é, agora, o de jardineiro da natureza e não o de responsável pela segurança alimentar” (Idem, p. 46).

O rural, que era considerado como fato sociológico, passa assim a ser visto como um fato físico. Enquanto estudiosos começam a questionar a dualidade campo/cidade, a sociedade civil mantém e produz tal oposição. Vale ressaltar que, mesmo mantendo essa

posição de subordinação e de complementariedade ao urbano, o mundo rural não representaria mais uma ruptura com o urbano, e as transformações que lhe são atribuídas na atualidade não resultariam na sua necessária descaracterização, mas em uma possível emergência de novas formas de sociabilidade e de identidades tidas como rurais. (CARNEIRO, 2005, p.8).

Ao se tratar da identidade dos povos do campo é preciso, portanto, considerar que as relações com o meio urbano são muito menos rígidas, ao contrário do que normalmente vemos na legislação e mesmo em estudos acadêmicos. Barth (2000), utilizando-se do conceito de fronteira, nos ajuda a entender que o que define um grupo são as fronteiras sociais, não seu conteúdo cultural ou o território por ele ocupado. Para o autor, “se um grupo mantém sua identidade quando seus membros interagem com outros, disso decorre a existência de critérios para determinação de pertencimento, assim como as maneiras de assinalar este pertencimento ou exclusão” (BARTH, 2000, p. 34). As fronteiras culturais permitem ao sujeito se ver em relação a um grupo majoritário e assim definir-se enquanto outro grupo, destacando, como salienta Barth, os aspectos que determinam o pertencimento ou exclusão ao grupo. Entretanto, o estar na fronteira não significa necessariamente a ruptura com o grupo social de origem, pois as transformações oriundas dessas trocas culturais, como mudanças nos hábitos, formas de se relacionar com os outros e com a natureza, a ampliação da percepção do mundo "expressam-se de maneira irregular e diversificada, segundo os interesses e a posição social dos atores, o que não implica, necessariamente, uma ruptura decisiva no tempo nem no espaço" (CARNEIRO, 2005, p. 10). Além disso, “não é mais aceito falar em um rural exclusivamente agrícola ou de um urbano que não inclua também possibilidades de construção de identidades rurais” (Ibidem). Nesse sentido,

a heterogeneidade social, ainda que produza uma situação de tensão, é também responsável pelo enriquecimento do tecido social, sem que isso resulte, necessariamente, em uma descaracterização das identidades culturais territorializadas. Ao contrário, a diversidade pode atuar no sentido de consolidar essas identidades ao possibilitar a consciência de si na relação com o outro, o que pode contribuir, por exemplo, para a definição de uma identidade urbana no interior de uma localidade tida como rural e vice-versa (Ibidem). 
Por tal razão, não é possível considerar que todo o campesinato brasileiro constitua uma identidade única, pois as pessoas "participam de universos de discurso múltiplos, mais ou menos discrepantes; constroem mundos diferentes, parciais e simultâneos, nos quais se movimentam. A construção cultural que fazem da realidade não surge de uma única fonte e não é monolítica” (BARTH, 2000, p. 113).

Pina Cabral (2003) ressalta que o self está ligado a várias identidades socioculturais, o que ele chama de identificações cruzadas. O autor entende que a criação da pessoa social é um processo de identificação com os outros. No entanto, esse processo, de dinâmica complexa, se dá em dois movimentos em que a pessoa se identifica com o outro, mas também visualiza as características que a distinguem desse outro.

Para o autor, a identidade pessoal é formada por um conjunto de solidariedades primárias ou formativas adquiridas ainda na infância, através da unidade social primária, mas que, segundo ele, ultrapassa a simples noção de família das línguas modernas. Cabral traz a concepção de família como a construção de um projeto que os próprios agentes sociais elaboram. Para ele, as pessoas constroem a forma e conteúdo de suas famílias à medida que precisam responder aos desafios a elas colocados. Esse processo é revalidado por todos os membros a partir dos conflitos que ao longo do tempo surgem, nos quais a identidade familiar é colocada em pauta por aqueles que dela partilham. Assim, as representações coletivas sobre família são modificadas a partir das próprias experiências de seus membros com relação ao seu projeto familiar.

Ao se analisar a identidade do campo, faz-se fundamental considerar as organizações familiares, tão importantes no meio rural. As contribuições de Pina Cabral possibilitam pensar a construção identitária dos povos do campo reconhecendo a importância da família nesse processo. O autor mostra como diferentes características presentes nos membros da família - como formas de nomeação, características físicas, comportamentais ou morais - compõem a construção da pessoa familiar. "Cada pessoa individual (tanto nos seus aspectos físicos como nos seus aspectos comportametais) é concebida como brotando de uma substância comum à família” (PINA CABRAL, 2003, p. 165). Nesse sentido, fica claro que a identidade de uma pessoa está ligada à identidade dos familiares (ou dos corpos familiares ${ }^{1}$ ) com quem é identificada. "O trabalho de construção do self e da nossa identidade pessoal é largamente um trabalho de síntese destas variadas identificações” (Idem, p.166).

Crescer junto, como membro de uma família é, para Pina Cabral, a principal embora não seja a única, fonte de identificações que constitui uma pessoa. "O corpo familiar faz parte da pessoa familiar” - integrando, portanto, o nome familiar e o comportamento familiar, por referência às lendas familiares (PINA CABRAL, 2003, p. 165), que são formadas pelo lado pessoalizado das narrativas individuais (fato ocorrido com determinada pessoa) e por seu lado generalizado (característica generalizada da pessoa: bonita, instável, corajosa, etc.), ambas em movimento constante. Cada nova geração pode recorrer em sua construção identitária a dois patrimônios familiares (que se multiplicaram de acordo com o número de gerações), que se combinam e recombinam. "Cada novo membro da família que vai deixando a sua história de vida feita vai funcionando como

\footnotetext{
${ }^{1}$ Composto por aqueles que constituem a organização familiar, inclusive padrinhos e outros membros da comunidade, que também exercem papel importante na construção identitária.
} 
um campo de combinação lendária” (Idem, p. 167). Nesse sentido, "a pessoa individual é formada em consubstancialidade com a sua família” (Idem, p. 168), ou a "pessoa cria a família tanto quanto é criada por ela” (Idem, p. 153).

Nesse processo de construção identitária, as novas gerações lidam com as tensões que as cercam, as fronteiras existentes entre os grupos sociais, e vão construindo sua identidade, pois "cada um de nós 'sai' a muitas pessoas, com características, personalidades e histórias de vida muito diversas” (Ibidem, p. 151). Por tal razão, estudos sobre os povos do campo precisam atentar para esse sujeito, que, dentro de um dinâmico processo, constitui e se constitui membro de um grupo social.

\section{Considerações finais: a construção de um objeto de estudo a partir da escola do campo}

A discussão teórico-acadêmica sobre educação do campo precisa, portanto, dialogar com as inúmeras questões do campo empírico, com o objetivo de levá-las ao plano político. Entre infraestrutura intra e extraescolar, práticas de sala de aula e formação docente, em diálogo com as diferenças de cada grupo, bem como com a construção de parcerias entre os envolvidos no processo de educação do campo, há inúmeros caminhos para as pesquisas.

Canário (2000), partindo do contexto de Portugal, enfatiza que a educação rural é tema periférico nas investigações científicas daquele país. Ele discute quatro colocações que vê como fundamentais para repensar a educação rural. A primeira delas refere-se ao entendimento de que o desenvolvimento de uma educação rural diz respeito ao futuro sustentável do mundo real, ultrapassando a visão de um problema do sistema escolar. A segunda consideração refere-se à afirmação da dimensão política das lutas do campo. Segundo o referido autor (2000, p.128),

a questão da escola em meio rural, pelas implicações societais para que remete, pode constituir um bom analisador para fazer sobressair a distinção entre uma visão técnica e gestionária dos problemas educativos e uma visão que recoloca a questão educativa no centro do debate político filosófico, na continuidade da tradição tão bem representada por Paulo Freire, para quem projeto educativo e projeto político constituíam realidades indissociáveis.

A terceira colocação tenta entender o mundo rural como meio de resistência à lógica de mercado, construindo novas alternativas ao mercado, considerando e reafirmando os valores do campo. Por fim, Canário considera que as práticas educativas desenvolvidas no meio rural podem contribuir para repensar a forma escolar, ao mesmo tempo em que cooperam para a revitalização de seu próprio espaço, ou seja, o campo. A partir desta última colocação, o autor ressalta três pontos que poderiam orientar um programa de pesquisa sobre a temática, partindo de uma visão mais ampla sobre o processo educativo. O primeiro deles diz respeito ao que ele chama de "abordagem ecológica da ação educativa”, entendida como um processo que abarca diversos atores e instituições, numa perspectiva indissociável entre contexto local, escola e família. O segundo ponto refere-se a considerar o sujeito como produtor de saber. Nessa perspectiva, a escola passa a ter sentido para os estudantes, já que a concepção de educação "passa a ser entendida como um trabalho que cada sujeito realiza sobre si próprio, para aceder a um 
conhecimento de si, dos outros e do mundo" (CANÁRIO, 2000, p. 136). Por fim, o terceiro aspecto está ligado à valorização da educação para além dos espaços escolares, mas com uma lógica de promover a articulação entre educação formal e não formal, atividades escolares e não escolares, bem como entre educação de crianças e educação de adultos, de modo a "fazer coincidir um projeto educativo globalizado com um projeto globalizado de educação” (Idem, p. 137).

A educação do campo tem se apresentado como uma luta que ultrapassou os limites dos movimentos sociais e que, ao trabalhar com outras parcerias, tem tido maior alcance e visibilidade da agenda política. Há uma busca de estratégias bastante inovadoras, o que resulta na diversidade de experiências na formação educativa de seus sujeitos e de possibilidades de trabalho. Há, portanto, um campo aberto para estudos, sejam eles voltados para as práticas educativas ou para os processos de implementação das políticas públicas, e muitos outros, que precisam ainda ser conhecidos.

Barth (2000) apresenta inúmeras contribuições para a pesquisa em educação do campo ao enfatizar a necessidade de romper com um olhar unificador para a cultura local, em busca de harmonia e consistência lógica. Nessa perspectiva, o autor propõe um conjunto de considerações para a análise da cultura de determinados contextos sociais.

A primeira delas refere-se à expressão "significado é uma relação". Para Barth essa afirmação orienta os procedimentos de descoberta, fazendo com que o olhar do pesquisador se atente para a ligação entre "qualquer meio de expressão e a pessoa que usa ou responde a esse meio", possibilitando que o significado dos objetos culturais para os sujeitos pesquisados seja elucidado, e que o contexto e a práxis que o envolvem sejam também apreendidos.
A segunda consideração proposta por Barth está ligada ao pensamento de que "cultura é distributiva, compartilhada por alguns e não por outros”. Tal afirmação sugere que, ao se analisar a cultura de determinado grupo social, é preciso atentar ao fato de que "as estruturas mais significativas da cultura talvez não estejam em suas formas, mas sim em sua distribuição e padrões de não-compartilhamento" (Idem, p.128). Cada produto cultural é vivenciado por cada pessoa de modo diferente, ou seja, a experiência de determinada prática cultural é que produz as diferenças entre as pessoas, e não as reduz, como equivocadamente por vezes se entende. De acordo com Barth, é essa percepção que possibilita ao pesquisador entender como se dá a produção e reprodução da cultura.

Em sua terceira consideração, Barth mostra que é preciso verificar a posição ocupada pelos atores do contexto analisado. Para ele, cada pessoa está em uma posição em que reúne diversas correntes culturais, ou seja, seu posicionamento reflete e permite "relacionar as pessoas às múltiplas tradições que elas adotam e que as impulsionam" (Idem, p. 138). O autor ressalta que essa ideia de posicionamento das pessoas auxilia na compreensão de variados processos sociais.

Por fim, o autor enfatiza que é preciso entender que as intenções dos atores individuais, bem como sua interpretação dos eventos, não estão ligadas aos resultados ou consequências desses eventos. Para Barth, a atenção a esta questão permite ao pesquisador lidar com os fenômenos sem desconsiderar as interpretações oriundas do contexto estudado.

Esses e os demais caminhos analíticos que aqui apresentei constituem modos de pensar uma educação do campo que contemple as formas identitárias de seus sujeitos/atores. Pretendi também fomentar a 
construção de parcerias entre os envolvidos na construção de uma educação do e no campo, mostrando que tais parcerias constituem uma proposta de formação dos mais diversos povos do campo, na qual as dimensões teóricas e práticas sejam mais integradas ao se beneficiar das contribuições das diferentes instâncias formativas em sua organização. Esse é um caminho necessário e indispensável para a educação do campo.

\section{Referências}

ANTUNES-ROCHA, M. Educação do campo: convergências e tensões no campo da formação e do trabalho docente (Apresentação) In: SOARES, L. et al. (Orgs.). Educação do campo: convergências e tensões no campo da formação e do trabalho docente. Belo Horizonte: Autêntica, 2010. (ENDIPE 2010). p. 465-468.

.; MARTINS, A. (Orgs.). Educação

do campo: desafios para a formação de professores. Belo Horizonte: Autêntica, 2010. (Caminhos da Educação do Campo)

ARROYO, M. G.; CALDART, R.; MOLINA, M. Por uma educação do campo. Petrópolis: Vozes, 2004.

ARROYO, M. G. Políticas de formação de educadores (as) do campo. Caderno Cedes, Campinas, v.27, n.72, p. 115-116, maio/ago. 2007.

BARTH, F. O guru, o iniciador e outras variações antropológicas. Tradução de Jonh Cunh Comerford. Rio de Janeiro: Contra Capa Livraria, 2000.

BRASIL. Decreto n. 7.352. Dispõe sobre a política de educação do campo e o Programa Nacional de Educação na Reforma Agrária - PRONERA. De 4 de novembro de 2010.
BRASIL. Ministério da Educação. Resolução CNE/CEB n. 1, de 3 de abril de 2002. Institui as diretrizes operacionais para a educação básica nas escolas do campo. Diário Oficial da União, Brasília, DF, 9 de abril de 2002. Seção 1, p. 32.

CALDART, R. Por uma educação do campo: identidade e políticas públicas. Brasília, 2002.

CANÁRIO, R. A escola no mundo rural: contributos para a construção de um objecto de estudo. Educação, Sociedade \& Culturas, Lisboa, n. 14, p. 121-139, 2000.

CANÁRIO, R. A prática profissional na formação de professores. In: PAIVA, Bartolo. Formação profissional de professores no ensino superior. Porto: Porto Editora, 2001. p. 31-45.

CARNEIRO, M. J. Apresentação. In: MOREIRA, R. J. (Org.). Identidades sociais: ruralidades no Brasil contemporâneo. Rio de Janeiro: DP\&A Editora, p. 7-15.

FOERSTE, E. Parceria na formação de professores. São Paulo: Cortez, 2004.

HAGE, S. Concepções, práticas e dilemas das escolas do campo: constrastes, desigualdades e afirmação de direitos em debate. In: SOARES, L. et al. (Org.). Convergências e tensões no campo da formação e do trabalho docente. Belo Horizonte: Autêntica, 2010. (ENDIPE 2010), p. 460-477.

LIMA, E. N. Novas ruralidades, novas identidades. Onde? In: MOREIRA, R. J. (Org.). Identidades sociais: ruralidades no Brasil contemporâneo. Rio de Janeiro: DP\&A Editora, p. 41-65.

NÓVOA, A. O passado e o presente dos professores. In: NÓVOA, A. (Org.). Profissão professor 3. 2. ed. Porto: Porto Editora, 2000. p. 09-32. (Colecção Ciências da Educação). 
O regresso dos professores. Comunicações da conferência: desenvolvimento profissional de professores para a qualidade e para a equidade da aprendizagem ao longo da vida. Portugal: Presidência Portuguesa do Conselho da União Europeia, 2007, p. 21-28.

PERRENOUD, P. Formar professores em contextos sociais em mudança: prática reflexiva e participação crítica. Revista Brasileira de Educação. n. 12, set-dez, 1999. p.5-21.

PINA CABRAL. O homem na família: cinco ensaios de antropologia. Lisboa: Imprensa de Ciências Sociais, 2003.

ROLDÃO, M. do C. Formar para a excelência profissional - pressupostos e rupturas nos níveis iniciais da docência. Educação e Linguagem, ano 10, v. 1, n. 15, São Bernardo do Campo, SP: UMESP, p. 18-42, jan-jun. 2007. p. 18-42.

ROLDÃO, Maria do Céu. Profissionalismo docente em análise - especificidades dos ensinos superior e não superior. Revista Nuances, São Paulo: UNESP, ano XI, n. 13, jan./ dez., 2006, p. 108-126.

SILVA, L. Concepções, práticas e dilemas das escolas do campo: a alternância pedagógica em foco. In: SOARES, L. et al. (Orgs.). Convergências e tensões no campo da formação e do trabalho docente. Belo Horizonte: Autêntica, 2010. (ENDIPE 2010). p. 425-440.

SNOEK, M. O envolvimento das escolas e dos professores na aprendizagem dos professores: ao encontro de parcerias e de comunidades aprendentes. Comunicações da conferência: desenvolvimento profissional de professores para a qualidade e para a equidade da aprendizagem ao longo da vida. Portugal: Presidência Portuguesa do Conselho da União Europeia, 2007, p. 68-81.

SOUZA, M. Educação do campo: políticas, práticas pedagógicas e produção científica.
Educação \& Sociedade, Campinas, v. 29, n.105, p. 1089-1111, set./dez. 2008.

TARDIF, M. Princípios para guiar a aplicação dos programas de formação inicial para o ensino. In: ENDIPE, 14 Porto Alegre: EDIPUCRS, 2008. Anais... v. 1. p. 17-46.

VENDRAMINI, C. Educação e trabalho: reflexões em torno dos Movimentos Sociais do campo. Caderno Cedes, Campinas, v. 27, n. 72, p. 121-135, maio/ago. 2007.

Recebido em: 09/05/2012

Aceito em: 19/06/2012 